Mr. N. Hendry (Rotax, Ltd.). Mr. Nethercot's paper dealt with the recording of high-speed transient phenomena by hot-cathode glass-bulb tubes, and examples were shown of wave-forms of $20 \mathrm{Mc}$./sec. and above. In single transient recording the beam traverses the screen only once, and the exposure time of the film is therefore determined by the duration of the glow from the screen, since the actual traverse time may be only a fraction of a microsecond. Photography by direct contact of the film with the screen has so many disadvantages that it is only suitable for transients of simple wave-shape where blurring of the trace and curvature of the screen do not affect the result appreciably. The most satisfactory method is by means of a specially designed camera.

Since the majority of the light emitted from a bluescreen tube (the optimum material for recording) is in the blue-violet region, it is not necessary to use an achromatic lens; further, the corrections necessary for a high-grade camera lens are not required for oscillographic recording at a fixed distance. The best results are obtained with ortho emulsions ; with panchromatic films the glow of the tube cathode frequently caused fogging on the centre of the record. Mr. N. Hendry, in dealing with the requirements of both cameras and tubes for recording, pointed out that small changes in the setting of the brilliancy control make large differences in the apparent recording sensitivity due to change in spectral emissivity of the screen with beam current. For many purposes, particularly where the reproduction of records is not required and the highest speed is not necessary, recording paper is as satisfactory as film, and more economical. The usual mercuric iodide intensifier gives good results, as does also a silver intensifier. In the discussion which followed, Dr. H. Moss (A. C. Cossor) spoke of the correction necessary for screen curvature of the tube, and Mr. G. Parr (Electronic Engineering) showed four simultaneous traces on recording paper taken from two gas-focused tubes with electronic switching of the beam.

\section{The Clinical Society of London, 1868-1907}

IN his recent presidential address on this subject before the Clinical Section of the Royal Society of Medicine, Dr. J. D. Rolleston said that the formation in 1868 of the Clinical Society of London, the parent of the Clinical Section of the Royal Society of Medicine, was mainly due to Dr. Headlam Greenhow and Dr. (afterwards Sir John) Burdon Sanderson, who were both assistant physicians of Middlesex Hospital, the latter being afterwards appointed Waynflete professor of physiology and eventually regius professor of medicine at Oxford. According to Dr. Rolleston, the most interesting historical event connected with the Clinical Society was the first medical description in Great Britain of X-rays, which was made before it nearly fifty years ago. Early in 1896, the Society invited"Prof. Silvanus Thompson to tell its members about the new discovery; a special meeting was held on March 30, 1896, and was attended by nearly four hundred members. Later, numerous cases illustrating the diagnostic and therapeutic value of $\mathrm{X}$-rays were reported at meetings of the Society and recorded in its Transactions. A remarkable custom in the practice of the Society was the frequent establishment of special committees to discuss various subjects or individual cases. The most important of these committees were those on myxodema, the periods of incubation and contagiousness of certain infectious diseases and the antitoxin of diphtheria. The course of the Society was successful from the first. At the time of its amalgamation in 1907 with sixteen other societies it numbered $\mathbf{5 7 2}$ ordinary members and 17 honorary members. The first meeting was held on January 10, 1868, under the presidency of Sir Thomas Wilson, who was regarded at the time as the greatest English physician of the century and was author of a text-book on medicine which was without a rival for more than thirty years.

\section{Early Science in the United States}

Two recent issues of the Proceedings of the American Philosophical Society (No. 1, vol. 86, 1942, and No. 3, vol. 87,1943 ) contain some interesting historical material and illustrations. The first, bearing the title "The Early History of Science and Learning in America with Especial Reference to the Work of the American Philosophical Society during the Eighteenth and Nineteenth Centuries", contains papers read before the Society at its mid-winter meeting in February 1942, and is inspired by the fact that that year saw the close of two hundred years of activity by the Society, which was organized by Franklin in 1743. It certainly seems a good plan to prepare for such a celebration as a bicentenary by the preliminary presentation of papers of this kind, in which various contributors deal with the Society's early activities in a wide range of fields, including, among others, agriculture, meteorology, climatology, engineering, vertebrate palæontology, and so on ; there is also an interesting biographical study of James Logan (1674-1751) and a carefully documented account of a memoir by Rafinesque that has been generally overlooked.

The other issue, entitled "Thomas Jefferson", contains papers read before the Society in celebration of the bicentenary of its third president, that great American, Thomas Jefferson, in April of 1943, at the actual bicentenary of the foundation of the Society, which was also the bicentenary of Jefferson's birth. Various contributors ably discuss Jefferson's life and times, his political philosophy, and his many scientific interests and pursuits. Dr. Harlow Shapley's paper on Jefferson as a natural philosopher was printed in Nature of August 14, p. 178. The figures of Franklin, Jefferson and Rittenhouse stand out once more in these pages, and fitly in these days we are reminded of Jefferson's oath of "eternal hostility against every form of tyranny over the mind of man". It is perhaps strange that in two places there recurs the old claim that Hadley's quadrant, "with the aid of which the European nations traverse the globe", was invented by the American, Godfrey, although this matter has been cleared up long ago.

\section{The High-Frequency Marine Radio Unit}

AN original conception of the Federal Telephone and Radio Corporation, now being adopted by ship architects in the United States, is the marine highfrequency unit-an entirely self-contained, complete, high-frequency ship installation, including transmitter, receiver and power equipment in a single housing with projecting shelf for operating purposes. In addition to providing a simple, flexible and effective way of supplying long-distance communication facilities over a continuously variable frequency range of 2-24 m.c. to any ship, it possesses advantages as regards installation, training, operating and servicing comparable with the marine radio unit. The development of these two units enables ship designers 
and marine architects to determine well in advance the exact space requirements needed for a complete modern radio room installation for both medium and high frequency. Waste of valuable capacity in the ships' structures can thus beavoided, and, in fact, the new units are already influencing the design of ships' radio rooms. An article by E. J. Girard (Elec. Comm., 21 , No. $2 ; 1943$ ) describes the new high-frequency unit, its circuit features, power supplies and installa. tion. The new equipment employs the unit construction principle for shipboard radio installations. Highfrequency radio transmitting and receiving equipment supplements standard frequency installations to provide, through choice of proper frequencies, means of direct communication with points far beyond the range of standard-frequency working. Since long-distance communication on high frequencies is accomplished with relatively low power, economy of operation is maintained even though the range is vastly extended. With elimination of ship-to-ship relaying of messages, accuracy and reliability are irnproved and communication with home ports is accelerated.

\section{Eclipse of the Sun, Sept. 21, 194I, in the U.S.S.R.}

A SPECIAL publication of the Academy of Sciences of the U.S.S.R., which has somewhat belatedly reached Great Britain, deals with the eclipse of September 21, 1941, and contains four papers written before the eclipse. The first, by A. Michailov, gives a detailed calculation of the circumstances of the eclipse in southern Siberia, and includes two charts from which the times of beginning and ending of the partial eclipse and its magnitude can be obtained for any point in the U.S.S.R. The second paper, by the same author, gives computations of the corpuscular eclipse, using four different velocities of particles, namely, $5000,3000,1600$ and $800 \mathrm{~km}$./sec., and assuming various sizes for the emitting surface of the sun, from a point to the full disk. A chart shows also the lines of totality for the optical ionospheric eclipse, at heights of $100,150,220,300$ and $500 \mathrm{~km}$. A paper by B. Fessenkoff contains the plan of campaign as worked out by the Eclipse Commission of the Academy of Sciences, gives a general summing-up of recent experience in eclipse expeditions, and describes fairly fully the technique to be used in the astrophysical observations, which are concerned largely with the corona. Finally, P. Tverskoy discusses the geophysical problems to be investigated : mainly the radio exploration of high atmospheric levels in order to determine the relative importance of corpuscular and ultra-violet radiation there; secondly, the investigation of the effect on the solar radiation of the various parts of the atmosphere, including its lower layers; and lastly, an attack on the inverse problem, namely, how the eclipse affects physical conditions in the lower atmosphere. No detailed results have yet reached Great Britain, but a preliminary note (J. Phys. U.S.S.R., 6, 1 ; 1942) gives ground for hope that much of the work planned was in fact carried out successfully.

\section{Typhus in Palestine}

Accordine to the Lancet of October 16, there have been 23 deaths from an outbreak of typhus during the past eight months in Palestine. The southern districts were chiefly affected, and the Department of Health has prepared special delousing units and portable showers for use in future cases. The disease is thought to have been introduced from neighbouring countries, especially Egypt. Murine typhus conveyed by rats is endemic in Palestine, but the present epidemic, which is more serious, is lice-borne and has not been seen in Palestine since the end of the War of 1914-18. A vaccine has been used with good effect, and a special laboratory for research and control of typhus has been opened under the charge of Prof. Kligler, head of the Department of Bacteriology and Hygiene (see also NATURE of November 27, p. 627).

\section{South African Bored Stones}

PART 4 of "The Bored Stones of Southern Africa" by A. J. H. Goodwin (Univ. of Cape Town : Comm. from the School of African Studies, Pt. 4. 2s.) has recently reached Great Britain. It deals with (a) the bored stones from the Cape of Good Hope and $(b)$ certain elongated types. Together with the previous papers dealing with these special types of stone objects, this further statistical work will be very useful to the student of the Stone Age in South Africa.

\section{University of Edinburgh}

THE University of Edinburgh has received intimation of a bequest by Dr. William Llewellyn Pryce Bevan, of Alton, Hants, of approximately $£ 22,000$ for the promotion of the teaching or the advancement of medical science.

The Polish School of Medicine at the University of Edinburgh has added to its. teaching staff Prof. Maria Gutowska (medicine) and Dr. A. Jablonski (natural philosophy).

\section{Announcements}

THE Committee of Privy Council for Medical Research has allowed amendments to the charter of the Medical Research Council, simplifying the rules governing the retirement of members of the latter body and increasing the number of members by one. By further Orders of the Committee of Privy Council, made after consultation with the president of the Royal Society and with the Medical Research Council, Prof. L. J. Witts, Nuffield professor of clinical medicine in the University of Oxford, and Prof. J. R. Learmonth, surgeon to H.M. Medical Household in Scotland, professor of surgery in the University of Edinburgh, and surgeon-in-ordinary, Edinburgh Royal Infirmary, have been appointed to be members of the Medical Research Council.

The Finney-Howell Research Foundation, Inc., announces that all applications for fellowships for next year must be filed in the office of the Foundation, 1211 Cathedral Street, Baltimore, Maryland, by January 1, 1944. This Foundation was provided for in the will of the late Dr. George Walker of Baltimore for the support of "research work into the cause or causes and the treatment of cancer". Fellowships carrying an annual stipend of 2,000 dollars are awarded for the period of one year, with the possibility of renewal up to three years.

Dr. F. W. EDRIDGE-Green has pointed out that it is incorrect to attribute to Theodor Engelmann the discovery of the cones and pigment cells of the retina (NATURE, Nov. 13, p. 560). Engelmann's most important work was the discovery of the movements of Deiter's cells and the pigment cells of the retina under the influence of light. Kölliker described the rods and cones of the retina in $\mathbf{1 8 5 4}$. 